AperTO - Archivio Istituzionale Open Access dell'Università di Torino

\title{
Genome-wide variability and selection signatures in Italian island cattle breeds
}

\section{This is the author's manuscript}

Original Citation:

Availability:

This version is available http://hdl.handle.net/2318/1686978

since 2019-02-05T17:48:08Z

Published version:

DOI:10.1111/age.12697

Terms of use:

Open Access

Anyone can freely access the full text of works made available as "Open Access". Works made available under a Creative Commons license can be used according to the terms and conditions of said license. Use of all other works requires consent of the right holder (author or publisher) if not exempted from copyright protection by the applicable law. 
This is the author's final version of the contribution published as:

Cesarani, A; Sorbolini, S; Criscione, A; Bordonaro, S; Pulina, G; Battacone, G; Marletta, D; Gaspa, G; Macciotta Nicolò Pietro Paolo,

Genome-wide variability and selection signatures in Italian island cattle breeds, ANIMAL GENETICS, 49: 371:383, 2018, doi: 10.1111/age.12697

The publisher's version is available at:

https://onlinelibrary.wiley.com/doi/full/10.1111/age.12697

When citing, please refer to the published version.

Link to this full text:

http://hdl.handle.net/2318/1686978

This full text was downloaded from iris-Aperto: https://iris.unito.it/ 
3 A. Cesarani*, S. Sorbolini*, A. Criscione $\uparrow$, S. Bordonaro $\uparrow$, G. Pulina*, , G. Battacone*, D. Marletta†, G. Gaspa*, N.P.P. Macciotta*

* Dipartimento di Agraria, Università degli Studi di Sassari, 07100 Sassari, Italy

† Dipartimento di Agricoltura, Alimentazione e Ambiente, Università degli Studi di Catania, 95131 Catania, Italy.

${ }^{\S}$ Agenzia FORESTAS, Regione Autonoma della Sardegna, 09123 Cagliari, Italy

\section{Summary}

In the present study, a sample of 88 animals belonging to four local (Modicana, Sarda, Sardo-Bruna and Sardo-Modicana) and one cosmopolitan (Italian Brown Swiss) cattle breeds were genotyped with a medium density SNP beadchip and compared in order to investigate their genetic diversity and the existence of selection signatures. A total of 43,012 SNPs scattered across all twenty-nine autosomal chromosomes were retained after the data quality control. Basic population statistics, Wright Fixation results of Multi-Dimensional scaling and admixture analysis the Sardo-Bruna is more similar to the 
the Modicana rather than to the Sarda breed. Results of the present work confirm the usefulness of Single Nucleotide Polymorphisms in deciphering the genetic architecture of livestock breeds.

Keywords: indigenous breeds, selection signatures, inbreeding, admixture, biodiversity

\section{Introduction}

The bovine domestication occurred presumably about 8-10 thousand years ago in southwest Asia (Zeder 2017). This process led to the zebuine and taurine breeds (Loftus et al. 1994; Upadhyay et al. 2016) derived both from the extinct wild aurochs (Bos primigenius) that spread in Europe and Africa in successive waves of migration. With domestication, cattle acquired a large variety of distinctive traits compared to their wild ancestors: for example, they became smaller in size and developed the capacity to adapt to various environments. During the Neolithic revolution, cattle accompanied human migrations and crosses between individuals of different ethnic groups generated a gene flow that changed the genetic makeup of their populations (Ajmone-Marsan et al. 2010).

The continuously increasing demand for work, milk and meat has enhanced between population differences over the centuries. In particular, changes in the farming systems, intense implementation of artificial selection, crossbreeding, and widespread use of artificial insemination that occurred in the last decades resulted in a huge genetic improvement of few highly specialized cattle breeds. However, as a consequence the within breed genetic variability has been seriously constrained in these populations (Brotherstone and Goddard, 2005). Biodiversity has been drastically endangered, a relevant reduction in the number of farmed cattle breeds has been observed leading to the extinction of many local breeds. Indigenous populations, better suited to extensive farming but not very productive, have been often abandoned in favor of highly productive breeds (Scherf 2000; Medugorac et al. 2009).

Concerns about climate changes, ethical issues, and evolution of consumer needs, including ecosystem services and landscape protection, are bringing towards sustainable livestock farming 
systems. Such an evolving situation seems to offer new opportunities to indigenous breeds, because of their strong linkage to the production area, large genetic variability, and great fitness. Local breeds, are now considered as important reservoirs of resilience and biodiversity (Giovambattista et al. 2001). Their genomes represent an ideal model for studying and understanding the evolutionary history of livestock species, essential goal for evolutionary biology and population genetics. Moreover, local breeds represent a source of income in marginal areas (Ruto et al. 2008) and a chance to answer to the environmental changes (Medugorac et al. 2009). Their typical products support a sustainable development of the rural environment and respond to new consumer demands for healthy foods.

In Italy there is a particular attention for biodiversity, due to the high number of native animal and plant populations distributed throughout the whole country (Maiorano et al. 2007). Seventeen indigenous cattle breeds have been officially recognized by the Italian Ministry of Agriculture. Of particular interest is the situation of four cattle breeds farmed in extensive traditional systems in the two main Italian Islands, Sicily and Sardinia. The Sarda (SAR) breed is present in the Island of Sardinia since about 3,000 years BC. It originates from west Mediterranean cattle populations (mainly from the Iberic peninsula) with influences from North African and Middle East breeds (Della Maria 1936; Brandano et al. 1983a). At the end of the XIX century, crossbreeding with Brown Swiss (BSW) bulls imported from Switzerland and Modicana (MOD) bulls imported from Sicily were carried out in order to improve the aptitude of SAR to draught, milk and meat production respectively. These crosses have led to the current Sardo-Bruna (SB) and SardoModicana (SM) breeds, respectively. The three Sardinian breeds have been officially recognized in 1985 with the establishment of the Herd book. The current population size, based on the number of animals recorded in the Herd book, is 25,315 and 923 herds for the SAR, 2,822 and 150 herds for the SM, and 33,662 and 1,426 herds for the SB respectively (www.aia.it).

The Modicana herdbook was established since 1952. Currently there are 5,209 animals recorded in the herd book, farmed in 235 herds (www.aia.it). An early genetic characterization of these breeds 
was carried out using morphologic measurements (Brandano et al.1983b), milk and blood protein polymorphisms (Brandano et al. 1983c). Recently SM and MOD were compared in a study on coat color genetic determinism using the Melanocortin 1 receptor gene (Guastella et al. 2011) and the distribution of Runs of Homozygosity (ROH) was studied in MOD by Mastrangelo et al. (2016). The SAR, MOD, and BSW can be considered as founder breeds and SB and SM are the derived ones. In this work, a comparison between the five breeds is carried out using a medium density (50K) SNP panel in order to investigate the genetic diversity and in particular to assess the extent of diversity between pure-breeds and derived crosses. Moreover, gene discovery was performed in the genomic regions that exhibited difference between breeds.

\section{Materials and methods}

\section{Animals and genotypic data}

A total of 88 animals of five different breeds were genotyped in outsourcing with the Illumina BovineSNP50 beadchip: 22 BSW, 27 MOD, 19 SAR, 10 SB, and 12 SM, respectively. Genomic DNA was obtained from blood samples for SB, MOD, SM, and from nasal swab for SAR, using the NucleoSpin DNA rapidLyse Kit (Macherey-Nagel) according to manufacturer's instructions. For BSW animals, genotype data were generated within the SELMOL research project using the Genomix kit (Talent, Trieste, Italy). Animals of local breeds were randomly sampled from different herds located in various areas of Sardinia and Sicily. Given the difficulty in gathering large samples in local breeds, criteria used in the present work to include animals in the analysis were absence of relatedness, distribution in the territory, morphological appearance and information based on farmer interviews.

Since BSW animals were genotyped using Illumina BovineSNP50 v1 BeadChip in contrast to the other genotypic data (Illumina BovineSNP50 v2), common markers were retained and remapped on the UMD 3.1 release of the Bovine genome assembly. Only autosomal SNPs were considered. 
Quality control was performed with Plink 1.9 (Purcell et al. 2007). Animals with a call rate > 95\% were retained. SNP selection was based on call rate $(>97.5 \%)$, minor allele frequency (MAF $>0.05)$, and significant deviation for Hardy -Weimberg equilibrium $(P<0.00001)$. After quality control, 43,012 common SNPs between the two Beadchip versions were retained. Missing genotypes were imputed using Beagle 4 (Browning \& Browning, 2016).

\section{Heterozygosity, Minor allele frequency and Linkage Disequilibrium}

Heterozygote count (HET) and the minor allele frequency (MAF) were calculated for each SNP separately by breed using Plink 1.9. Linkage disequilibrium (LD) between markers was calculated within $1000 \mathrm{~kb}$ distance (McKay et al. 2007) using Haploview (Barrett et al. 2005).

\section{Multi-dimensional scaling and admixture analysis}

The Multi-Dimensional scaling plot (MDS) and admixture analysis were performed using the Zanardi pipeline (Marras et al. 2016) and "ggplot2" R package (Wickham, 2009). In MDS analysis, a principal component (PC) analysis is performed on the genomic correlation matrix $\mathbf{G}$ and PC scores are calculated for each individual. In order to confirm the animal classification in five different breeds, the K parameter of admixture was fixed at 5 .

\section{Wright Fixation Index and LOWESS}

Ten pair-wise comparisons were performed using the Wright fixation index $\left(\mathrm{F}_{\mathrm{sT}}\right)$ calculated using the equation proposed by Nei (1977):

$\mathrm{F}_{\mathrm{ST}}=\left(\mathrm{H}_{\mathrm{T}}-\mathrm{H}_{\mathrm{s}}\right) / \mathrm{H}_{\mathrm{T}}$

where $\mathrm{H}_{\mathrm{r}}$ is the observed total heterozygosity and $\mathrm{H}_{\mathrm{S}}$ is the observed heterozygosity in each population, respectively. For the $\mathrm{F}_{\mathrm{ST}}$ calculation, an in house Python script was used. In order to simplify the graphic interpretation of raw $\mathrm{F}_{\mathrm{sT}}$ data, a Locally Weighted Scatterplot Smoothing 
(LOWESS) procedure was used (Pintus et al. 2014). The LOWESS is a local smoothing regression in which the space of the independent variable (in this case the progressive order of adjacent SNPs along the chromosome) is fragmented into different intervals for which separate regressions are fitted. The method is aimed at removing noise from raw data and at improving graphical representation. A smoothing parameter corresponding to an interval of 20 SNPs for each local regression was used.

A common problem when interpreting genetic difference metrics is the lack of proper statistical tests. Some authors have proposed to fix a threshold based on the $\mathrm{F}_{\mathrm{st}}$ distribution (Kijas et al. 2012; Pintus et al., 2014). Although the distribution of raw $\mathrm{F}_{\text {st }}$ values tends to be skewed, LOWESS smoothed values could be considered approximately normally distributed. Thus, the significance threshold in the present work was set to three standard deviation from the mean. Such a stringent threshold was adopted considering the limited sample size.

\section{Runs of homozygosity}

Runs of Homozygosity (ROH) were detected using the Zanardi pipeline. Some constraints were fixed in order to limit the number of spurious ROH segments (Marras et al. 2015): the minimum length of ROH was set at $1 \mathrm{Mb}$, homozygous segments of minimum fifteen SNPs were considered and neither heterozygous or missing genotypes were allowed. The following ROH statistics were calculated by animal and by breed: number of $\mathrm{ROH}$, the average $\mathrm{ROH}$ length (in $\mathrm{Mb}$ ) and the sum of all $\mathrm{ROH}$ segments by animal $\left(\mathrm{S}_{\text {вон }}\right.$, in $\left.\mathrm{Mb}\right)$. $\mathrm{ROH}$ were grouped into five classes of length $(1<\mathrm{Mb}$ $\leq 2,2<\mathrm{Mb} \leq 4,4<\mathrm{Mb} \leq 8,8<\mathrm{Mb} \leq 16$ and $\mathrm{Mb}>16)$.

The ROH-based inbreeding coefficient $\left(\mathrm{F}_{\text {вон }}\right)$ for each animal was calculated as

$$
\mathrm{F}_{\mathrm{ROH}}=\frac{\sum \mathrm{S}_{\mathrm{ROH}(\mathrm{8M} \mathrm{Mb})}}{\text { Lgen }}
$$


where $\mathrm{L}_{\mathrm{gen}}$ is the total length of genome. The minimum length of ROH to be included in the calculation was fixed to $8 \mathrm{Mb}$ based on previous reports in cattle (Marras et al. 2015). Moreover, the $\mathrm{ROH}$ count per $\mathrm{SNP}\left(\mathrm{SNP}_{\text {вон }}\right)$, i.e. the number of animals having a given SNP included in a $\mathrm{ROH}$ (Nothnagel et al. 2010) was calculated. A threshold of 50\% was fixed to consider a $\mathrm{SNP}_{\text {вон }}$ value as significant.

\section{Gene discovery}

Gene discovery was performed in regions flagged by $\mathrm{F}_{\mathrm{ST}}$ values exceeding the control chart upper limit. Intervals spanning $0.25 \mathrm{Mb}$ upstream and downstream the significant marker were considered. Moreover, regions identified by ROH distribution were studied. In particular, markers having $\mathrm{SNP}_{\mathrm{ROH}}>50 \%$ within a breed were considered as significant and the region spanning 0.25 $\mathrm{Mb}$ upstream and downstream surrounding them was investigated. Annotated genes were retrieved from UCSC Genome Browser Gateway (http://genome.ucsc.edu./) and National Centre for Biotechnology Information (NCBI) (www.ncbi.nlm.nih.gov) databases.

\section{Results}

HET and MAF showed a little variation between the five considered breeds (Table 1). BSW showed smallest values of both HET and MAF, whereas MOD and SAR exhibited the largest values for these parameters, respectively.

A clear distinction between the breeds could be observed along the first axis (PC1) of the MDS plot (Fig. 1). In particular the PC1, that explains about $5.4 \%$ of the total variance, depicts a geographic cline: starting from the bottom of the graph there are individuals from BSW (origin from the Switzerland, North of Italy), then SAR and SB (centre of Italy), and at the top SM and MOD (native of Sicily, Southern Italy). Furthermore, it could be seen that along this dimension, SM breed is more similar to MOD than SAR. The second axis (PC2), explaining about 3\% of the total variance, 
highlights a separation within the SAR breed. The PC2 seemed to be able to discriminate animals according to the percentage of SAR genetic contribution: an increase in PC2 scores indicates the passage from SAR purebred to crosses, and then to MOD and BSW breeds. Population structure analysed by admixture (Fig. 2) revealed a clear definition of BSW animals (95\% assigned to a single cluster, the one of red colour), and less precise for MOD and SAR (90\% and 93\% assigned to two different clusters, respectively). Finally, also the derived breeds were grouped into two distinct clusters (70\% of both SB and SM cattle). The LD pattern (Fig. 3) shows the lowest value for MOD, the highest for BSW and SB, respectively.

The $\mathrm{F}_{\mathrm{sr}}$ comparison with the largest number of significant SNPs was SB vs SM, whereas the smallest was observed for BSW vs SM (Table S1). Figure 4 reports Manhattan plots of $\mathrm{F}_{\text {sт }}$ predicted by LOWESS for the comparisons between pure breeds and crosses. It can be observed that the highest $\mathrm{F}_{\text {Sт }}$ values between BSW and SB were found for BTA6 (Fig. 4a), with the top significant markers (Table S2) located between 38.20 and $38.83 \mathrm{Mb}$. In this region map some known genes controlling milk production traits (ABCG2, PKD2, SPP1, LAP3), and body size (NCAPG and LCORL) in cattle. BTA8 and BTA13 showed the highest $\mathrm{F}_{\text {гт }}$ peaks in the SAR vs SB comparison (Fig. 4b) with seven and three significant markers respectively (Table S2). In the region highlighted on BTA8 is located the microRNA2471 (MIR2471), whereas in the highlighted segment of BTA13 is annotated the Eukaryotic translation initiation factor 6 (EIF6) gene.

SAR and SM were different mainly on BTAs 7, 14, and 21 (Fig. 4c and Table S2). An interesting gene retrieved from the database was the Ubiquitin Protein Ligase E3A (UBE3A) that maps in the region between 2.1 and $2.3 \mathrm{Mb}$ of BTA21.

As far as the comparison between SM and MOD is concerned (Fig. 4d), the highest values of $\mathrm{F}_{\mathrm{sT}}$ have been found on BTAs 5, 16 and 20 (Table S2). On BTA20 the region from 70.9 to 71.7 $\mathrm{Mb}$ presents a QTL associated with milk somatic cell score. Moreover, this segment contains 
several annotated genes, among which of interest is the Solute Carrier Family 9 Member A3 (SLC9A3).

Finally, for the SM vs SB comparison the highest values of $\mathrm{F}_{\mathrm{sT}}$ have been detected on chromosomes 7 and 24 (Fig. 4e and Table S2). On BTA7, five significant markers define a region (47.2-47.3 Mbp) were the Transcription Factor 7 (T-Cell Specific, HMG-Box) (TCF7) gene maps.

The total number of detected $\mathrm{ROH}$ (Table 2) exhibited a large variation between breeds, with MOD and SM having the largest and the smallest value, respectively. The BSW had the largest average $\mathrm{ROH}$ length, even if together with a huge variability as evidenced by the value of the standard deviation (Table 2). This breed had also the highest average number of SNP per ROH (Table 2). On the contrary MOD showed the smallest values of both statistics. As expected, most represented $\mathrm{ROH}$ classes in all breeds were those of length $<4 \mathrm{Mb}$ (relative frequency ranging from 0.736 in BSW to 0.868 in MOD and SM, respectively). The largest number of ROH in the class of highest length $(>16 \mathrm{Mb})$ was observed in BSW, and it was markedly larger than in all the other considered breeds (Table 2).

$\mathrm{ROH}$ count per SNP showed some interesting peaks along the genome. The highest peak was observed on BTA6 for BSW at approximately 30-40Mb (Fig. 5a). In this region map several known genes as $A B C G 2$, SPP1, LCORL, NCAPG. BSW exhibited another signal between 10-30 Mb on BTA20 (Fig. 5b). Moreover, BTA1, BTA10 and BTA11 showed interesting signals of SNPs in homozygosity for over $50 \%$ of the animals. In particular, BSW showed a $\mathrm{SNP}_{\text {вон }}$ peak on BTA1 (Fig. 6a) between 103.5 and 105.5 Mb. On the same chromosome, a peak was detected for MOD at 139.0 Mb. On BTA10 an interesting homozygous region was observed in the SAR breed between 72.2 and $72.8 \mathrm{Mb}$ (Fig. 6b). Among the genes that map in this region the Dehydrogenase/Reductase 7 (DHRS7) can be mentioned. Finally, the SB showed a relevant value of $\mathrm{SNP}_{\text {вон }}$ on BTA11 (Fig. 6c) between 65.0 and $67.0 \mathrm{Mb}$ where the Ewing Tumor Associated Antigen 1 (ETAA1) was annotated. 
BSW exhibited also the largest average $\mathrm{F}_{\text {вон }}$ (Table 3) whereas the smallest value was observed by SM.

\section{Discussion}

The practice of crossbreeding has represented a major cause of gene flow across cattle populations, providing a relevant contribution to the shaping of worldwide current breeds. The history of the Sarda breed and its crosses with Modicana and Brown Swiss represents a typical example. Results of the present study confirm the genetic relationships between the considered breeds. The admixture analysis (Fig. 2) clearly detected the five different genetic groups, highlighting the genetic background of the crossbred derived population in comparison of the original purebreds. Furthermore, the analyses of the genome features with different approaches gave useful insights on effects of selection and environmental adaptation on the cattle genome.

A first indication was provided by basic population statistics. The lower genetic variability exhibited by the BSW in comparison with the other two pure-breeds, SAR and MOD, was expected due to the intense artificial selection this breed has been subjected to in the last decades (www.anarb.it). A low allelic diversity for BSW cattle in comparison with other cattle breeds has been already reported (Schmid et al. 1999; Melka \& Schenkel 2012).

The genome feature analysis carried out using the MDS decomposition, and the ROH detection highlighted an interesting structure of the considered sample of animals. The North-South geographical gradient highlighted by the first axis of the MDS is in agreement with several studies where a dimension reduction method is applied to molecular data on populations from different geographical origin (Price 2006; Chessa et al. 2009; Ciani et al. 2014). Also, the variation of the $\mathrm{ROH}$ statistics and of the inbreeding coefficient $\mathrm{F}_{\text {вон }}$ exhibited the same cline. In particular the average $\mathrm{ROH}$ length, the average number of SNP per $\mathrm{ROH}$, and the $\mathrm{F}_{\text {Rон }}$ showed an increase moving from South to North. This gradient was also confirmed by the LD analysis (Fig. 3). Purfield et al. 

(2012) found a higher number of ROH in cattle breeds of British Isles compared to other European breeds and ascribed such a diversity to the closed population histories of these cattle. Results obtained in the present study can be probably due to a low effective population size of BSW and to the population history of the SAR, MOD, and their crosses. A geographical South-North gradient in ROH feature distribution has been observed also in human populations (Nothnagel et al. 2010), and it has been explained with the most pronounced genetic isolation of Northern populations compared to Mediterraneans. The second axis of the MDS analysis highlights two clusters in the sample of Sarda cattle (Fig. 1). Previous studies on this population highlighted a large morphological heterogeneity (Brandano et al. 1984). Moreover, in the traditional extensive cattle farming system of Sardinia it is not very common to exchange bulls between herds, resulting in a high average relatedness of individuals within farm and a low degree of kinship among farms.

Different degree of genetic relationships between original and derived breeds have been observed. The similarity between SM and MOD was quite expected (Fig. 1). Although the first importation of MOD bulls from Sicily started at the end of the nineteenth century in the Montiferru area (CenterNorth Sardinia), it probably occurred again in more recent times and therefore the genetic component of Modicana purebred is still preserved into current SM. On the other hand, the separation between SB and the two founder breeds, i.e. BSW and SAR (Fig. 1), seems to indicate an absence of recent genetic exchange.

The genetic history of the breeds is also depicted by other structural elements of their genome, as their linkage disequilibrium (Fig. 3) and the extent of regions of autozygosity (Fig. 5 and 6). The intensive genetic selection of BSW in comparison with the other investigated breeds resulted in the highest level of LD and in the largest values of all $\mathrm{ROH}$ statistics. These results agree with previous reports on this breed (Ferenčaković et al. 2013; Marras et al. 2015). A previous study on MOD breed reported a smaller value of $\mathrm{F}_{\text {вон }}$ (Mastrangelo et al. 2016) but using different ROH settings (i.e. minimum number of SNP in a ROH equal to 40, minimum ROH length $4 \mathrm{Mb}$, two missing SNP 
allowed in a $\mathrm{ROH}$ etc.). An interesting result is the distribution across individuals of specific ROHs, i.e. a segment that starts and ends exactly in the same position. The largest ROH frequency was about 0.06 (Table 4) and it can be seen that in general local breeds tend to share ROH whereas the autozygous segment detected on BTA6 can be found only within the BSW breed. In particular, the latter ROH flagged a region where several known genes affecting milk traits are located. These results confirm the role of $\mathrm{ROH}$ as indicators not only of inbreeding but also of signatures of selection (Marras et al. 2014; Kim et al. 2015).

Signatures of selection were highlighted in the present study. Some of them flagged genome regions already detected in many studies on cattle. An example is represented by the markers exhibiting the largest $\mathrm{F}_{\mathrm{s \tau}}$ values in the BSW vs SB comparison, all located in the region of BTA6 spanning between $36-39 \mathrm{Mb}$ that harbors some known genes controlling milk production traits $(A B C G 2$, PKD2, SPP1, LAP3) (Olsen et al. 2005; Cohen-Zinder et al. 2005) and body size (NCAPG and LCORL) (Takasuga 2016) (Table S2). This region was also flagged by a significant value of ROH count per SNP in BSW.

Other two well known selection signatures were detected in BSW on BTA6 (Fig. 5a) by $\mathrm{SNP}_{\text {вон }}$ significant values (>50\%). The first was located at around $70 \mathrm{Mb}$, where the V-Kit Hardy-

Zuckerman 4 Feline Sarcoma Viral Oncogene Homolog (KIT) locus maps. This gene is involved in mammalian coat colour determinism (Fontanesi et al. 2010; Stella et al. 2010). The second signature of selection, at around $85 \mathrm{Mb}$, identified the caseins cluster (Blott et al. 2003). Another interesting peak value of $\mathrm{SNP}_{\text {вон }}$ was found on BTA20 (14-25 Mb) (Fig. 5b), in a region where a large QTL associated with milk protein percentage was reported (Ashwell et al. 2004). Among the several genes that map in this region, of interest is the Importin 11 (IPO11) locus. This gene has been found to be associated with the displacement of the abomasum in German Holstein cattle breed (Mömke et al. 2013). 
Interestingly, the $\mathrm{F}_{\mathrm{ST}}$ pairwise comparison between the SAR and the SB did not detect SNPs located in genomic regions known to contain genes associated with milk production traits. These results, together with the pattern highlighted by the MDS, confirm that current SB is closer to SAR than to BSW, probably due to backcrossing.

Of interest are the signatures of selection found in the comparisons between local breeds. Some of them include interesting genes that were found to be associated with fitness traits. In the comparison between the SAR and its derived SB, the seven highly significant SNPs found on BTA8 between 40.4 and 40.6 Mbp (Fig. 4b) identified a region where maps the microRNA2471 (MIR2471). In animals, microRNAs are molecules involved in diverse biological processes such as development, cell differentiation, proliferation and metabolism. They are among major post-transcriptional regulators of gene expression through promoting mRNA degradation or translational repression (Glazov et al. 2009; Guo et al. 2010; Meunier et al. 2013). Recently they have been found to be essential for the regulation of the immune response (Xiao \& Rajewsky 2009). The highest peak of $\mathrm{F}_{\mathrm{ST}}$ comparison between the SAR and the other derived breed, the SM, was detected on BTA14 (Fig. $4 \mathrm{c}$ and Table S2) in a region where maps the gasdermin $C(G S D M C)$ locus. This gene was associated to UV-protective eye pigmentation in Fleckvieh cattle (Pusch et al. 2012). Another peak was located on BTA21, between 2.1 and $2.3 \mathrm{Mb}$, where the Ubiquitin Protein Ligase E3A $(U B E 3 A)$ gene is annotated. This locus has been associated with the calving ease (Pausch et al. 2011; Meszaros et al. 2016) in cattle. This trait represents very often a distinguishing feature in indigenous breed that are mainly reared in extensive and semi-extensive systems (Boggio et al. 1988).

Other genes detected in the local breeds are related to milk production traits and fatty acid metabolism. Among genetic differences found between SM and MOD, of interest is the region located on BTA20, from 70.9 to $71.7 \mathrm{Mb}$. Among the annotated genes, is worth of mention the Solute Carrier Family 9 Member A3 (SLC9A3), involved in the rumen sodium transport (Rabbani et 
al. 2011). A high $\mathrm{Na}^{2+}$ tissue concentration improves milk production in warm/humid conditions

323 (Granzin \& Gaughan 2002). Moreover, a QTL associated with milk somatic cell score was reported in this region (Durán Aguilar et al. 2016). The comparison between the two derived breeds, i.e., SB vs SM. found a selection signature defined by five significant markers (47.2-47.3 Mbp) on BTA7, where maps the Transcription Factor 7 (T-Cell Specific, HMG-Box) (TCF7) gene. Recently, this locus was associated with milk production in Chinese Holstein (Mao et al. 2015).

An interesting candidate gene highlighted by $\mathrm{SNP}_{\text {вон }}$ in the SAR breed on BTA10 is the Dehydrogenase/Reductase 7 (DHRS7) locus. It catalyses the oxidation/reduction of a wide range of substrates, including retinoid and steroids (Haeseleer \& Palczewski 2000) and it has high expression levels in adipocytes and skeletal muscles (Wu et al. 2009). In addition, this gene is responsible for the final step in the cholesterol production (Porter 2000). This gene was already associated in Nellore cattle with the intramuscular fat deposition and composition (Cesar et al. 2014). Finally, another signature of selection that included a gene involved in fatty acid metabolism was found in the SAR vs SB comparison (three significant markers on BTA13 between 65.1 and $65.2 \mathrm{Mb}$ ) (Fig. 4b). This region harbours the Eukaryotic translation initiation factor 6 (EIF6) locus. This gene controls fatty acid synthesis and glycolysis in tissues responsive to insulin such as adipose and muscular.

\section{Conclusion}

Results of the present work confirm the usefulness of genome structural features in deciphering the genetic architecture of livestock breeds. The different approaches used to explore medium density SNP genotypes gave a comprehensive picture of genetic relationships between the three original and the two derived breeds, reflecting their recent genetic history. As expected, a larger heterogeneity was highlighted for the local breeds. Signatures of selection located in genomic regions harboring candidate genes for milk production traits have been detected in the comparisons involving the 
specialized BSW breed, whereas for local breeds the flagged genes involved in fitness and fatty acid metabolism. The study confirmed the importance of these populations as resevoir of biodiversity and as models for studying the genetic basis of adaptability.

\section{Acknowledgments}

This Research was funded by the Banco di Sardegna Foundation and by the Regional Government of Sardinia (project grant 07/G1-20, POR-FSE 2007-13). The author wishes to thank Dr. Salvatore Mele of Agenzia FORESTAS for his contribution to the animal sampling.

\section{References}

Ajmone-Marsan P., Garcia J.F. \& Lenstra J.A. (2010) On the origin of cattle: How aurochs became cattle and colonized the world. Evolutionary Anthropology: Issues, News, and Reviews 19, 148157.

Ashwell M.S., Heyen D.W., Sonstegard T.S., Van Tassell C.P., Da Y., VanRaden P.M., Ron M., Weller J.I. \& Lewin H.A. (2004) Detection of Quantitative Trait Loci Affecting Milk Production, Health, and Reproductive Traits in Holstein Cattle. Journal of Dairy Science 87, 468-475.

Barrett J.C., Fry B., Maller J. \& Daly M.J. (2005) Haploview: analysis and visualization of LD and haplotype maps. Bioinformatics 21, 263-265.

Blott S., Kim J.J., Moisio S., Schmidt-Küntzel A., Cornet A., Berzi P., Cambisano N., Ford C., Grisart B., Johnson D., Karim L., Simon P., Snell R., Spelman R., Wong J., Vikki J., Georges M., 
Farnir F. \& Coppieters W. (2003) Molecular dissection of a quantitative trait locus: a

phenylalanine-to-tyrosine substitution in the transmembrane domain of the bovine growth hormone receptor is associated with a major effect on milk yield and composition. Genetics 163, 253-266.

Boggio F., Pracchi R. \& Asole A. (1998) Atlante economico della Sardegna 1. Jaca Book, Edizioni Universitarie Jaca, Italia.

Borg I. \& Groenen P. (2003) Modern multidimensional scaling: theory and applications. Journal of

Educational Measurement 40, 277-280.

Brandano P., Asara P., Pulina G., Bolla P. \& Crimella C. (1983a). The Sardinian cattle. 1.

Morphological and biological characters. Annals of the Faculty of Agriculture of the University of Sassari 30, 161-177.

Brandano P., Asara P., Pulina G., Bolla P. \& Crimella C. (1983b) The Sardo- Modicana cattle

Breed. 1. Annals of the Faculty of Agriculture of the University of Sassari 30, 197-214.

Brandano P., Pulina G. \& Asara P. (1983c) The indigenous cattle of Sardinia. Breeds and herds

characteristics. Annals of the Faculty of Agriculture of the University of Sassari 30, 1-23.

Brotherstone S., \& Goddard M. (2005). Artificial selection and maintenance of genetic variance in 394 the global dairy cow population. Philos Trans R Soc Lond B Biol Sci. 360: 1479-1488.

Browning B.L. \& Browning S.R. (2016) Genotype imputation with millions of reference samples. The American Journal of Human Genetics 98, 116-126. 
398 Cesar A.S., Regitano L.C., Mourão G.B., Tullio R.R., Lanna D.P., Nassu R.T., Mudado M.A., 399 Oliveira P.S.N., do Nascimento M.L., Chaves A.S., Alencar M.M., Sonstegard T.S., Garrick D.J., 400 Reecy J.M. \& Coutinho L.L. (2014) Genome-wide association study for intramuscular fat 401 deposition and composition in Nellore cattle. BMC genetics 15, 39.

402

403 Ciani E., Crepaldi P., Nicoloso L. et al. (2014) Genome-wide analysis of Italian sheep diversity 404 reveals a strong geographic pattern and cryptic relationships between breeds. Animal Genetics, $\mathbf{4 5}$, $405 \quad 356-366$.

406

407 Chessa, B., F. Pereira, F. Arnaud, A. Amorim, F. Goyache et al. 2009. Revealing the history of 408 sheep domestication using retrovirus. Science 324, 532

409

410 Cohen-Zinder M., Seroussi E., Larkin D.M., Loor J.J., der Wind A.E., Lee J.H., Drackley J.K., 411 Band M.R., Hernandez A.G., Shani M., Lewin H.A., Weller J.I. \& Ron M. (2005) Identification of 412 a missense mutation in the bovine ABCG2 gene with a major effect on the QTL on chromosome 6 413 affecting milk yield and composition in Holstein cattle. Genome Research 15, 936-944.

Della Maria G. (1936) Ancient stories of Sardinian bovine breed. Rivista di Zootecnia 13, 47-57.

Durán Aguilar M., Román Ponce S.I., Ruiz López F.J., González Padilla E., Vásquez Peláez C.G.,

Bagnato A. \& Strillacci M.G. (2016) Genome-wide association study for milk somatic cell score in 419 Holstein cattle using copy number variation as markers. Journal of Animal Breeding and Genetics $420 \quad 134,49-59$. 
Ferenčaković M., Hamzić E., Gredler B., Solberg T.R., Klemetsdal G., Curik I., \& Sölkner J. (2013) Estimates of autozygosity derived from runs of homozygosity: empirical evidence from selected cattle populations. Journal of Animal Breeding and Genetics 130, 286-293.

Fontanesi L., Scotti E. \& Russo V. (2010) Analysis of SNPs in the KIT Gene of Cattle with Different Coat Colour Patterns and Perspectives to Use These Markers for Breed Traceability and Authentication of Beef and Dairy Products. Italian Journal of Animal Science 9, e42.

Giovambattista G., Ripoli M. V., Peral-Garcia P. \& Bouzat J. L. (2001) Indigenous domestic breeds as reservoirs of genetic diversity: the Argentinean Creole cattle. Animal Genetics 32, 240-247.

Glazov E.A., Kongsuwan K., Assavalapsakul W., Horwood P.F., Mitter N. \& Mahony, T.J. (2009) Repertoire of Bovine miRNA and miRNA-Like Small Regulatory RNAs Expressed upon Viral Infection. PLOS ONE 4, e6349.

Granzin B.C. \& Gaughan J.B. (2002) The effect of sodium chloride supplementation on the milk production of grazing Holstein Friesian cows during summer and autumn in a humid sub-tropical environment. Animal Feed Science and Technology 96, 147-160.

Guastella A.M., Sorbolini S., Zuccaro A., Pintus E., Bordonaro S., Marletta D. \& Macciotta N.P.P. (2011) Melanocortin 1 receptor (MC1R) gene polymorphisms in three Italian cattle breeds. Animal Production Science 51, 1039-1043.

Guo L \& Lu Z. (2010) Global expression analysis of miRNA gene cluster and family based on isomiRs from deep sequencing data. Computational Biology and Chemistry 34, 165-171. 
446 Haeseleer F. \& Palczewski K. (2000) Short-chain dehydrogenases/reductases in retina. Methods in enzymology 316, 372-383.

448

Kijas J.W., Lenstra J.A., Hayes B., Boitard S., Porto Neto L.R., San Cristobal M., Servin B.,

McCulloch R., Whan V., Gietzen K., Paiva S., Barendse W., Ciani E., Raadsma H., McEwan L.,

Dalrymple B., and International Sheep Genomics Consortium (2012) Genome-Wide Analysis of the

World's Sheep Breeds Reveals High Levels of Historic Mixture and Strong Recent Selection. PloS

Biology 10, e 10001258.

Loftus R. T., MacHugh D. E., Bradley D. G., Sharp P. M. \& Cunningham P. (1994) Evidence for 2757-2761.

Maiorano L., Falcucci A., Garton E.O. \& Boitani L (2007) Contribution of the Natura 2000 network to biodiversity conservation in Italy. Conservation Biology 21, 1433-1444.

460

Marras G., Gaspa G., Sorbolini S., Dimauro C., Ajmone-Marsan P., Valentini A., Williams J.L. \& 
469

470

471 Genetics 48, 121-128.

472

473

474 Genome wide linkage disequilibrium and genetic structure in Sicilian dairy sheep breeds. BMC

475 Genetics 15, 108.

476

477 Mastrangelo S., Tolone M., Gerlando R.D., Fontanesi L., Sardina M.T. \& Portolano B. (2016)

478 Genomic inbreeding estimation in small populations: evaluation of runs of homozygosity in three

479 local dairy cattle breeds. Animal 10, 746-754.

480

481

482

483

484

485

486

487

488

489

490

491

492

Marras G., Rossoni A., Schwarzenbacher, H., Biffani S., Biscarini F. \& Nicolazzi E.L. (2016)

Zanardi: an open-source pipeline for multiple-species genomic analysis of SNP array data. Animal

Mastrangelo S., Di Gerlando R., Tolone M., Tortorici L., Sardina M.T. \& Portolano B. (2014)

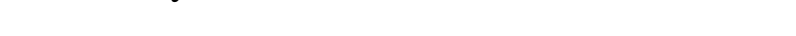

McKay S.D., Schnabel R.D., Murdoch B.M., Matukumalli L.K., Aerts J., Coppieters W., Crews D., Dias Neto E., Gill C.A., Gao C., Mannen H., Stothard P., Wang Z., Van Tassell C.P., Williams J.L., Taylor J.F. \& Moore S.S. (2007) Whole genome linkage disequilibrium maps in cattle. BMC Genetics 8, 74.

Medugorac I., Medugorac A., Russ I., Veit-Kensch C.E., Taberlet P., Luntz, B., Mix H.M. \& Förster M. (2009) Genetic diversity of European cattle breeds highlights the conservation value of traditional unselected breeds with high effective population size. Molecular Ecology 18, 3394-3410. Melka M.G. \& Schenkel F.S. (2012) Analysis of genetic diversity in Brown Swiss, Jersey and Holstein populations using genome-wide single nucleotide polymorphism markers. BMC Research Notes 5, 161. 
Mészáros G., Taferner R. \& Sölkner J. (2016) Pleiotropic and epistatic interactions between stillbirth and calving ease in cattle. Acta Agriculture Slovenica 5, 56.

Meunier J., Lemoine F., Soumillon M., Liechti A., Weier M., Guschanski K., Hu H., Khaitovich P. \& Kaessmann, H. (2013) Birth and expression evolution of mammalian microRNA genes. Genome Research 23, 34-45.

Mömke S., Sickinger M., Lichtner P., Doll K., Rehage J. \& Distl O. (2013) Genome-wide association analysis identifies loci for left-sided displacement of the abomasum in German Holstein cattle. Journal of Dairy Science 96, 3959-3964.

Nei M. (1977) F-statistics and analysis of gene diversity in subdivided populations. Annals of Human Genetics 41, 225-233.

Nothnagel M., Lu T.T., Kayser M. \& Krawczak M. (2010) Genomic and geographic distribution of SNP-defined runs of homozygosity in Europeans. Human Molecular. Genetics 19, 2927-2935.

Olsen H.G., Lien S., Gautier M., Nilsen H., Roseth A., Berg P.R., Sundaasen K.K., Svendsen M. \& Meuwissen T.H.E. (2005) Mapping of a Milk Production Quantitative Trait Locus to a 420-kb Region on Bovine Chromosome 6. Genetics 169, 275-283.

Pausch H, Wang X, Jung S, Krogmeier D, Edel C, et al. (2012) Identification of QTL for UVProtective Eye Area Pigmentation in Cattle by Progeny Phenotyping and Genome-Wide Association Analysis. PLoS ONE 7: e36346. 
518 Pausch H., Flisikowski K., Jung S., Emmerling R., Edel C., Götz K.U. \& Fries R. (2011) Genome519 Wide Association Study Identifies Two Major Loci Affecting Calving Ease and Growth-Related 520 Traits in Cattle. Genetics 187, 289-297.

522 Pintus E., Sorbolini S., Albera A., Gaspa G., Dimauro C., Steri R., Marras G. \& Macciotta N.P.P. 523 (2014) Use of locally weighted scatterplot smoothing (LOWESS) regression to study selection 524 signatures in Piedmontese and Italian Brown cattle breeds. Animal Genetics 45, 1-11. 525 526 527 528 529 530 531 532 533 534 535 536 537 538 539

540 541 542

Porter F.D. (2000) RSH/Smith-Lemli-Opitz syndrome: a multiple congenital anomaly/mental retardation syndrome due to an inborn error of cholesterol biosynthesis. Molecular Genetics and Metabolism 71, 163-174.

Price A.L., Patterson N.J, Plenge R.M., Weimblatt M.E., Shadick N.A. \& Reich D. (2006) Principal components analysis corrects for stratification in genome-wide association studies. Nature Genetics 38, 904-909.

Purcell S., Neale B., Todd-Brown K., Thomas L., Ferreira M.A.R., Bender D., Maller J., Sklar P., de Bakker P.I.W., Daly M.J. \& Sham P.C. (2007) PLINK: a toolset for whole-genome association and population-based linkage analyses. American Journal of Human Genetics 81, 559-575.

Purfield D.C., Berry D.P., McParland S. \& Bradley D.G. (2012) Runs of homozygosity and population history in cattle. BMC Genetics $\mathbf{1 3}, 70$.

R Core Team (2015) R: A language and environment for statistical computing. R Foundation for Statistical Computing, Vienna, Austria. URL https://www.R-project.org/. 
544 Ruto E., Garrod G. \& Scarpa R. (2008) Valuing animal genetic resources: a choice modeling 545 application to indigenous cattle in Kenya. Agricultural Economics 38, 89-98.

546

547 Scherf B.D. (2000) World watch list for domestic animal diversity (No. Ed. 3) Food and 548 Agriculture Organization (FAO).

549

550 Schmid B.M., Saitbekova N., Gaillard C. \& Dolf G. (1999) Genetic diversity in Swiss cattle breeds. 551 Journal of Animal Breeding and Genetics 116, 1-8.

Stella A., Ajmone-Marsan P., Lazzari B. \& Boettcher P. (2010) Identification of Selection 554 Signatures in Cattle Breeds Selected for Dairy Production. Genetics 185, 1451.

555

Takasuga A. (2016) PLAG1 and NCAPG-LCORL in livestock. Animal Science Journal 87, 159557 167.

Upadhyay M.R., Chen W., Lenstra J.A., Goderie C.R.J., MacHugh D.E., Park S.D.E., Magee D.A., 560 Matassino D., Ciani F., Megens H.J., van Arendonk J.A.M, Groenen M.A.M, \& European Cattle 561 Genetic Diversity Consortium, Crooijmans R.P.M.A. (2016) Genetic origin, admixture and 562 population history of aurochs (Bos primigenius) and primitive European cattle. Heredity 118, 169563176.

565 Wickham H. (2009) Gplot2: Elegant Graphics for Data Analysis. Springer-Verlag New York. 566 
567 Xiao C. \& Rajewsky K. (2009) MicroRNA control in the immune system: basic principles. Cell

568 136, 26-36.

569

570 Zeder M. (2017) Domestication and early agriculture in the Mediterranean basin: Origins, diffusion, 571 and impact. Proceedings of the National Academy of Sciences 105, 11592-11604.

572

573

574 
575 Table 1. Mean value of heterozygosity (HET) and Minor allele frequency (MAF) in the five breeds.

\begin{tabular}{lllll}
\hline & \multicolumn{2}{c}{ HET } & \multicolumn{2}{c}{ MAF } \\
\cline { 2 - 5 } & Mean & s.d. & Mean & s.d. \\
\hline BSW & 0.318 & 0.011 & 0.232 & 0.010 \\
MOD & 0.348 & 0.008 & 0.249 & 0.006 \\
SAR & 0.335 & 0.011 & 0.252 & 0.005 \\
SB & 0.343 & 0.012 & 0.251 & 0.007 \\
SM & 0.347 & 0.013 & 0.251 & 0.006
\end{tabular}

577 BSW = Italian Brown Swiss; MOD = Modicana;

578 SAR =Sarda $;$ SB =Sardo Bruna $;$ SM = Sardo Modicana.

579 
580 Table 2. Statistics of ROH size and frequency in the five investigated cattle breeds.

\begin{tabular}{lrrrrr}
\hline & \multicolumn{1}{c}{ BSW } & MOD & SAR & SB & SM \\
\cline { 2 - 6 } Average length $(\mathrm{Mb})$ & $3.9 \pm 5.0$ & $2.3 \pm 1.8$ & $2.9 \pm 2.4$ & $2.6 \pm 2.3$ & $2.4 \pm 2.0$ \\
Average number of SNP per ROH & $67.2 \pm 85.8$ & $40.2 \pm 30.3$ & $49.1 \pm 40.8$ & $44.7 \pm 39.1$ & $41.2 \pm 33.6$ \\
Number of ROH & & & & & \\
$1-2 \mathrm{Mb}$ & 780 & 1270 & 834 & 423 & 447 \\
$2-4 \mathrm{Mb}$ & 404 & 571 & 420 & 220 & 195 \\
$4-8 \mathrm{Mb}$ & 231 & 242 & 251 & 87 & 83 \\
$8-16 \mathrm{Mb}$ & 138 & 34 & 74 & 21 & 13 \\
$>16 \mathrm{Mb}$ & 56 & 2 & 2 & 4 & 2 \\
Total & 1609 & 2119 & 1581 & 755 & 740
\end{tabular}

581 BSW = Italian Brown Swiss; MOD =Modicana; SAR =Sarda; SB =Sardo Bruna; SM = Sardo 582 Modicana. 
Table 3. ROH-based inbreeding coefficient $\left(\mathrm{F}_{\mathrm{ROH}}\right)$

584 calculated using $\mathrm{ROH}>8 \mathrm{Mb}$.

\section{$\mathrm{F}_{\mathrm{ROH}}$}

\begin{tabular}{lllll} 
& Mean & s.d. & Max & Min \\
\hline BSW & 0.127 & 0.043 & 0.210 & 0.043 \\
MOD & 0.073 & 0.056 & 0.290 & 0.031 \\
SAR & 0.095 & 0.086 & 0.360 & 0.015 \\
SB & 0.080 & 0.078 & 0.282 & 0.019 \\
SM & 0.060 & 0.058 & 0.227 & 0.023
\end{tabular}

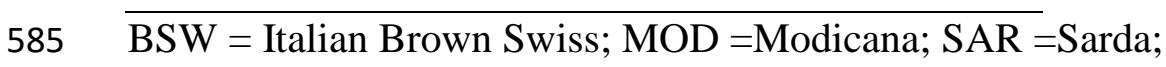

586 SB $=$ Sardo Bruna; $\mathrm{SM}=$ Sardo Modicana. 
587 Table 4. Most frequent $\mathrm{ROH}$ detected in the five breeds

\begin{tabular}{llllll}
\hline Chromosome & Start & End & Length $(\mathrm{Mb})$ & Frequency $^{1}$ & Breed \\
\hline 1 & 73924347 & 75505402 & 1.58 & 5 & SB, MOD,SAR \\
29 & 23762023 & 25780595 & 2.02 & 5 & SB, SM, MOD,SAR \\
6 & 32241952 & 34661866 & 2.41 & 5 & BSW \\
9 & 27516531 & 28538817 & 1.02 & 5 & SB, SM, SAR \\
9 & 821062 & 2677236 & 1.86 & 5 & SM, MOD, SAR, BSW
\end{tabular}

588 BSW = Italian Brown Swiss; MOD =Modicana; SAR =Sarda; SB =Sardo Bruna; SM = Sardo 589 Modicana.

$590 \quad{ }^{1}$ Number of individuals that possess the specific ROH across breeds

591 
Figure 1 Multi-Dimensional Scaling plot of the five investigated breeds: Italian Brown Swiss (BSW), Modicana (MOD), Sarda (SAR), Sardo-Bruna (SB) and Sardo-Modicana (SM).

Figure 2 Genetic structure and admixture plot obtained through coefficients of individual membership to clusters $(\mathrm{K}=5)$ assumed to be present in the sample of investigated breeds. Red columns $=$ cluster 1 ; Light green columns $=$ cluster 2 ; Blue columns $=$ cluster 3 ; Green columns $=$ cluster 4; Purple columns = cluster 5 .

Figure 3 Average LD $\left(\mathrm{r}^{2}\right)$ between markers within an interval of $1000 \mathrm{~kb}$ in the five Italian cattle breeds: Italian Brown Swiss (BSW), Modicana (MOD), Sarda (SAR), Sardo-Bruna (SB) and SardoModicana (SM).

Figure 4 Manhattan plot of $F_{\mathrm{sr}}$ values predicted by the LOWESS. a) Comparison between Italian Brown and Sardo-Bruna. b) Comparison between Sarda and Sardo-Bruna. c) Comparison between Sarda and Sardo-Modicana. d) Comparison between Sardo-Modicana and Modicana. e) Comparison between Sardo-Modicana and Sardo-Bruna. Red color dots indicate significant FST values (i.e. greater than 3 standard deviations from the mean).

Figure 5 Occurrence of SNP counted in a ROH measured by the percentage of animals belonging to the five investigated breeds for which a particular SNP falls into a ROH versus the position along the chromosome. a) Comparison of BTA6. b) Comparison of BTA20.

Figure 6 Occurrence of SNP counted in a ROH measured by the percentage of animals belonging to the five investigated breeds for which a particular SNP falls into a ROH versus the position along the chromosome. a) Comparison of BTA1. b) Comparison of BTA10. c) Comparison of BTA11. 
620

621

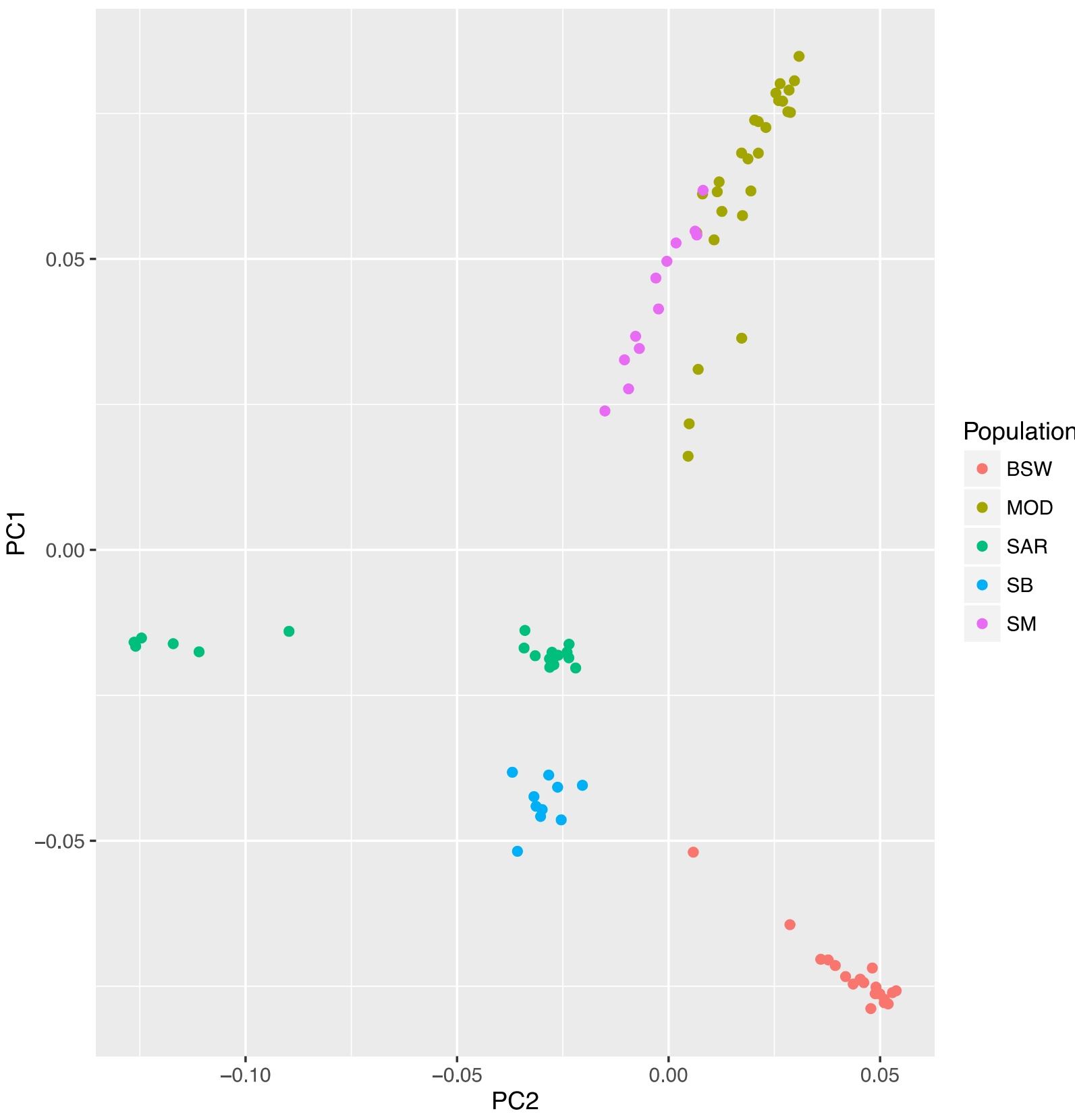

Figure 1

625

626

627 


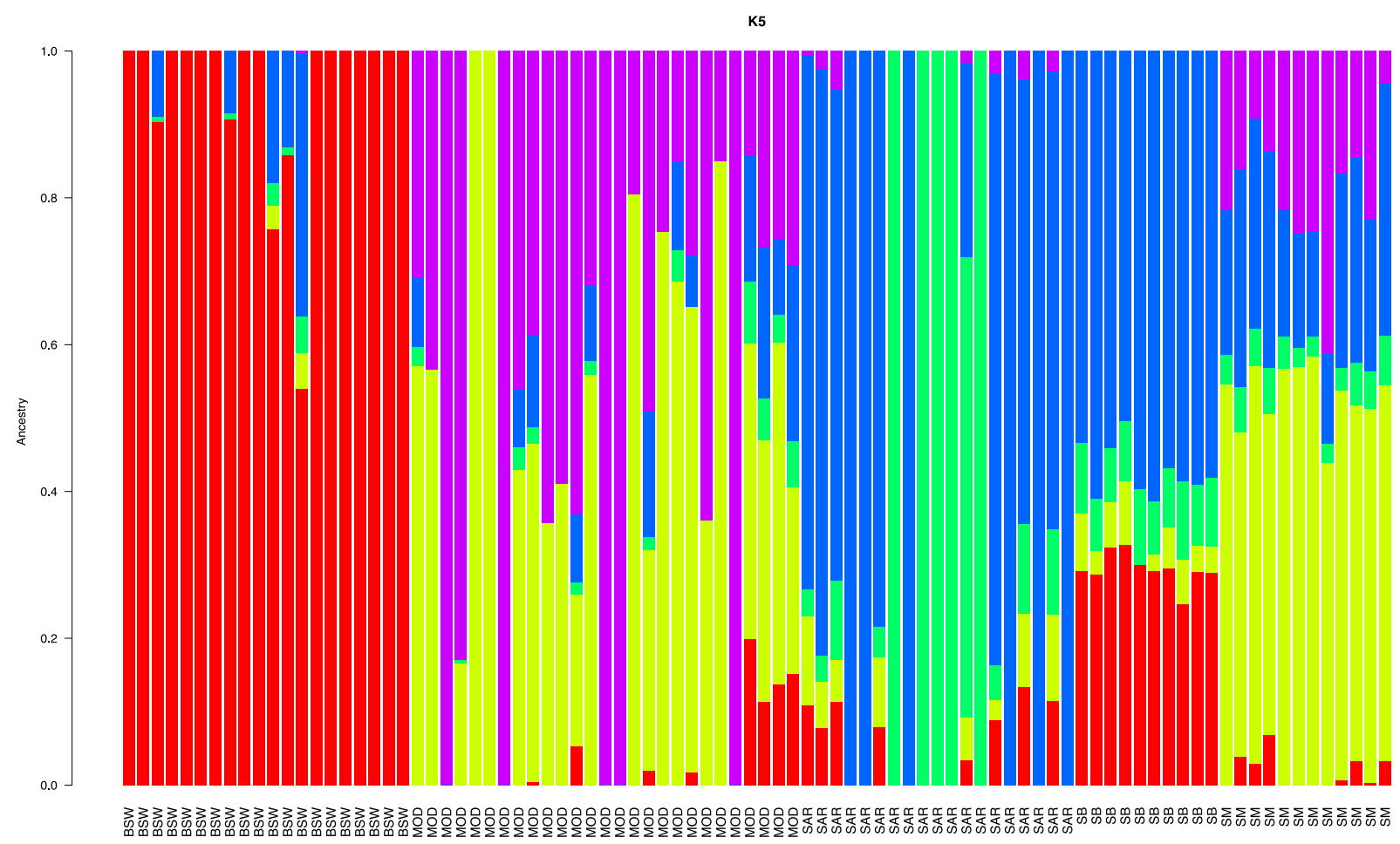

628

629

Figure 2

630

631

iris-AperTO 


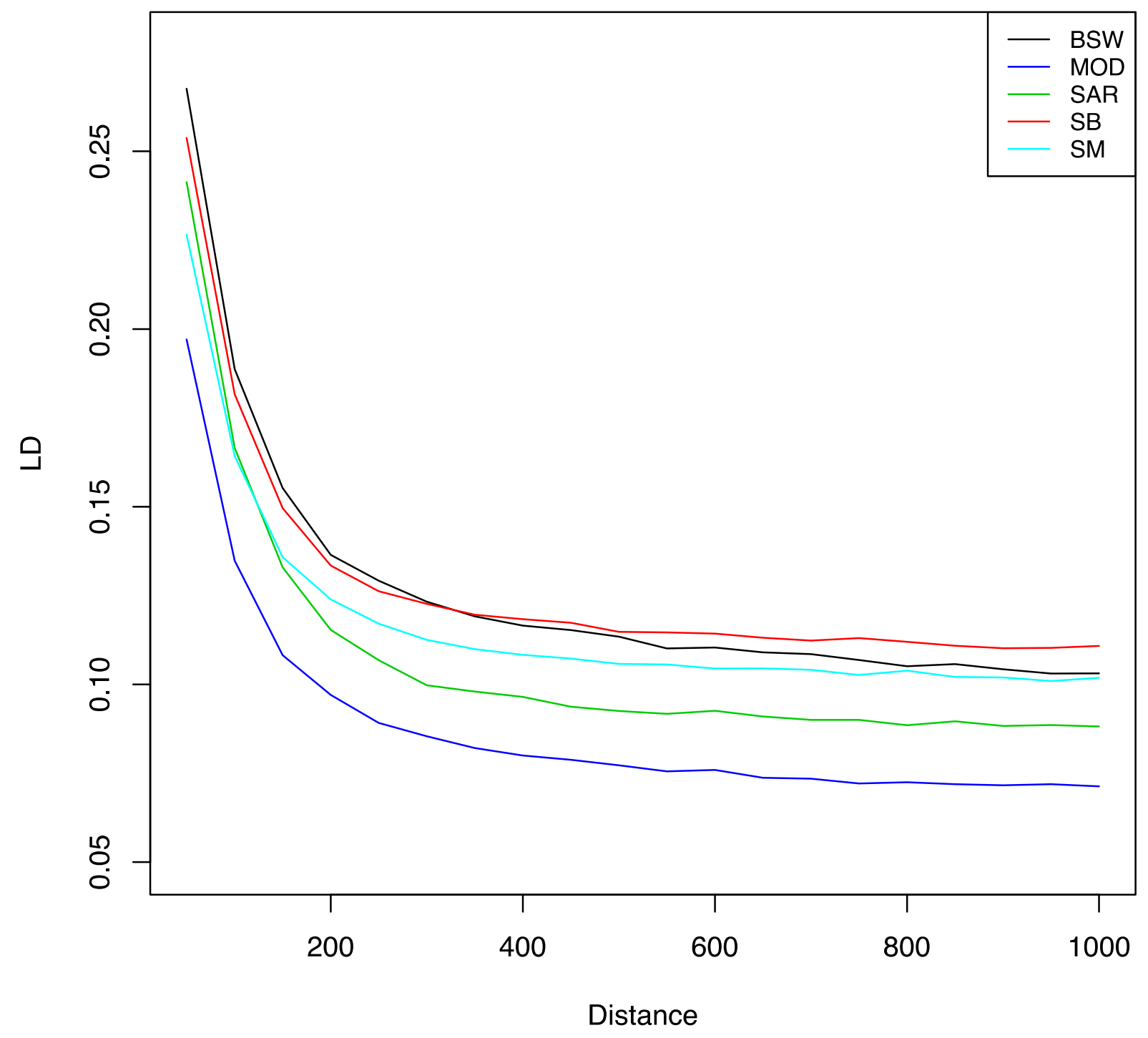

632

633

634 Figure 3 


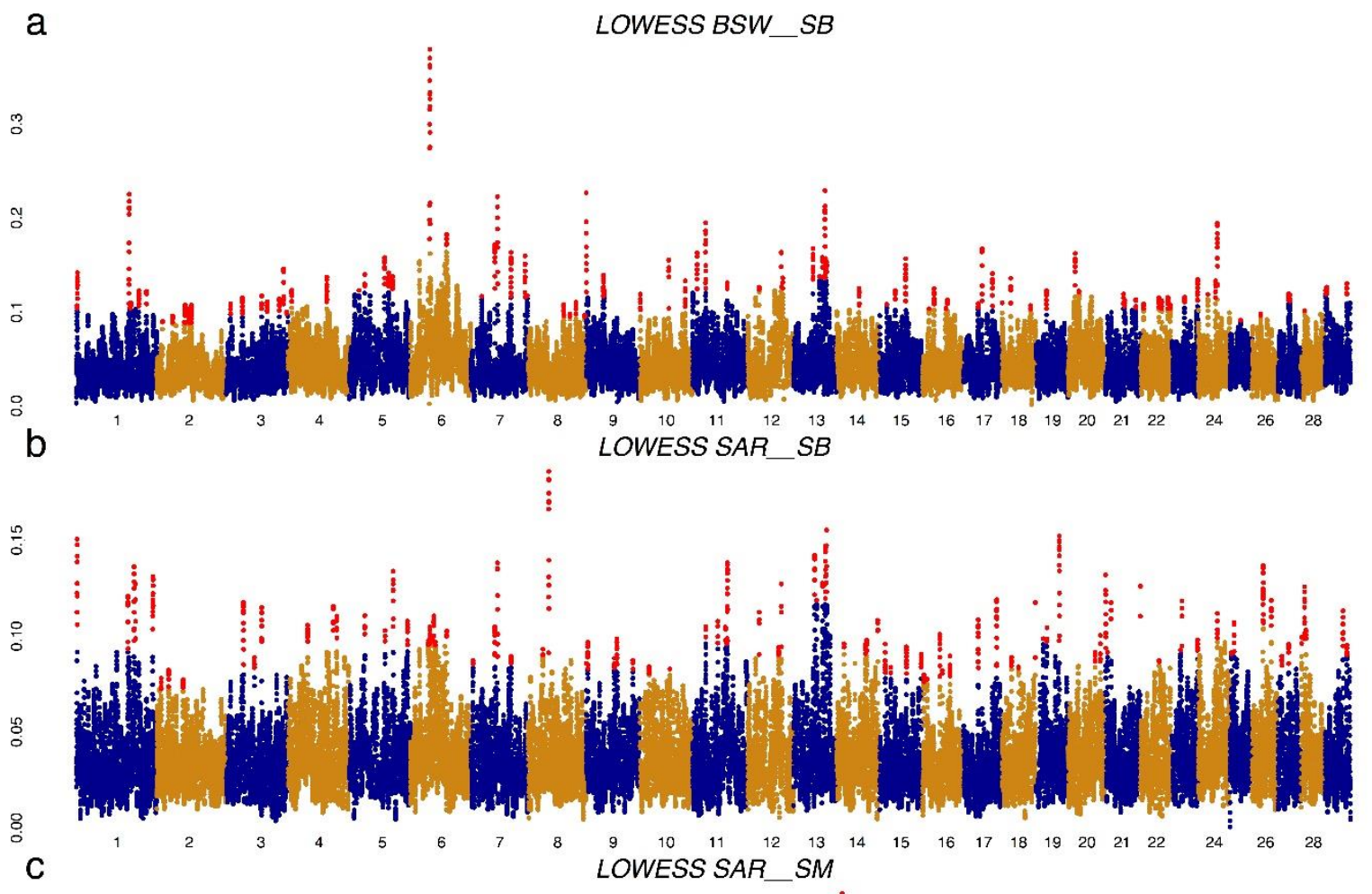

$\stackrel{\circ}{\circ}$
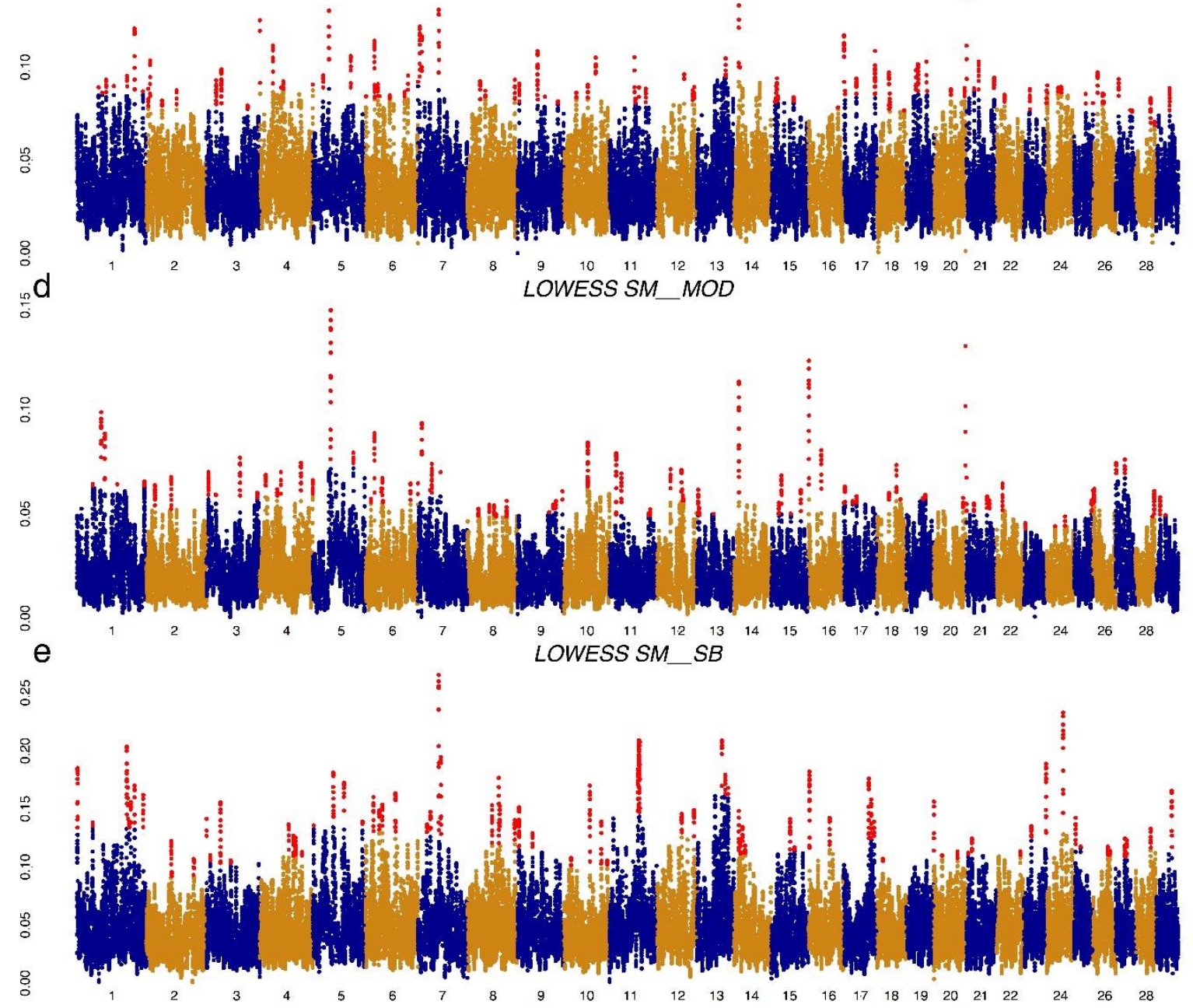
iris-AperTO 


\section{Figure 4}

a

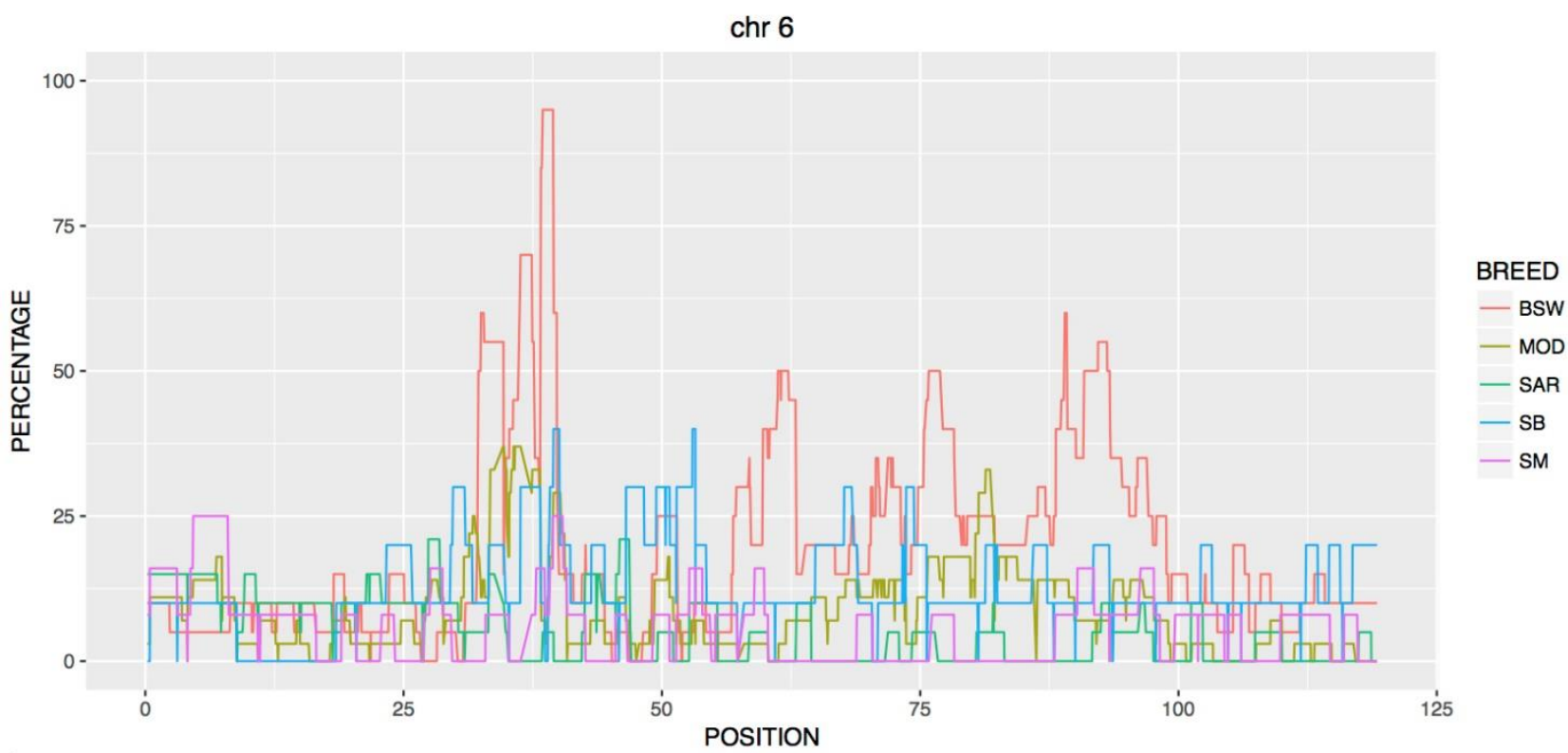

b

chr 20

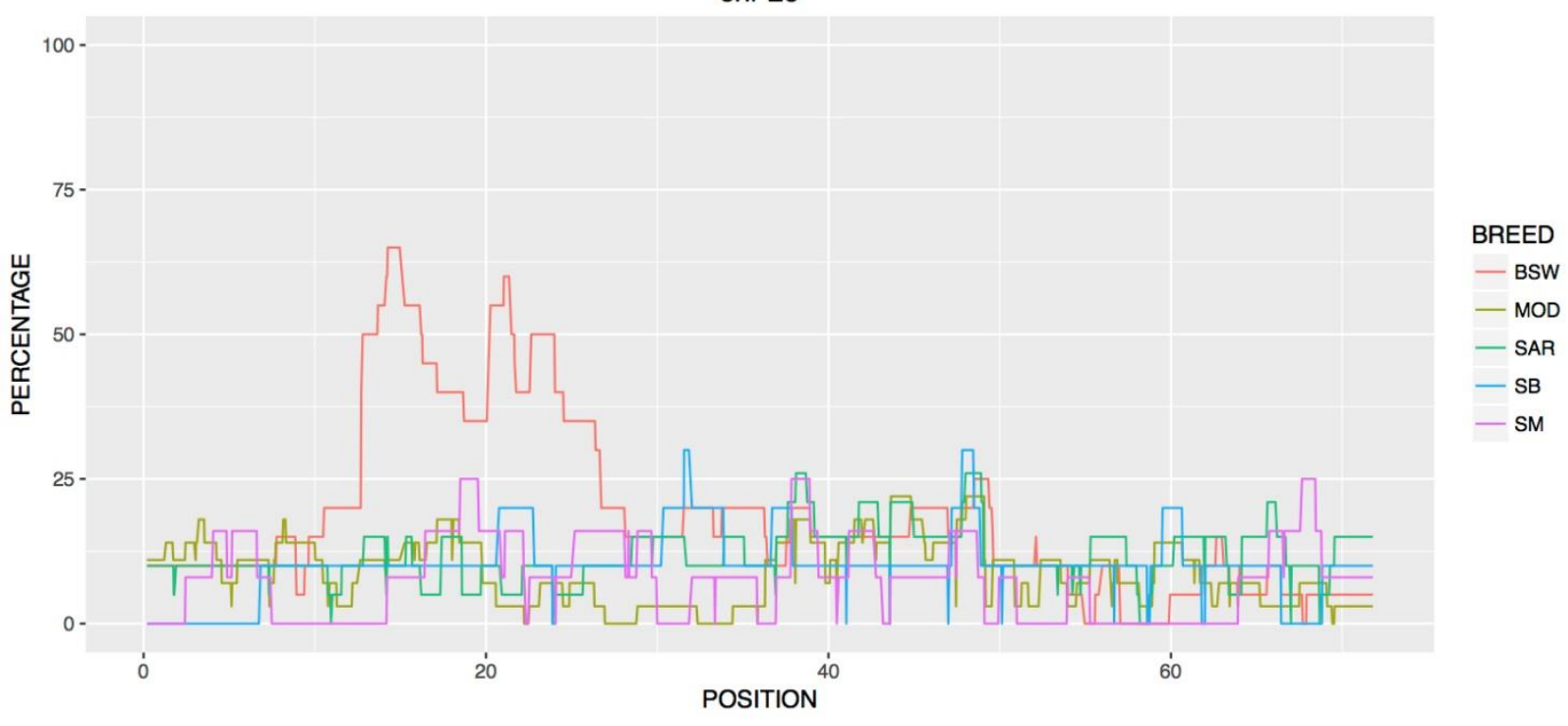

637

638 Figure 5 
a

chr 1

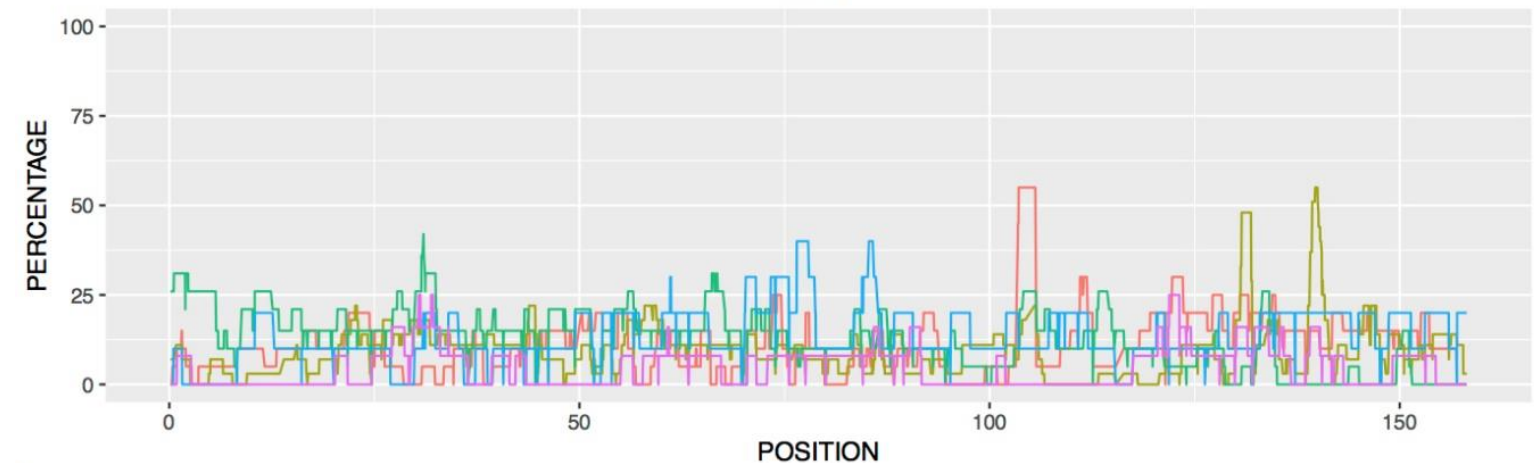

BREED

- BSW

- MOD

- SAR

- $\mathrm{SB}$

- SM

b

chr 10

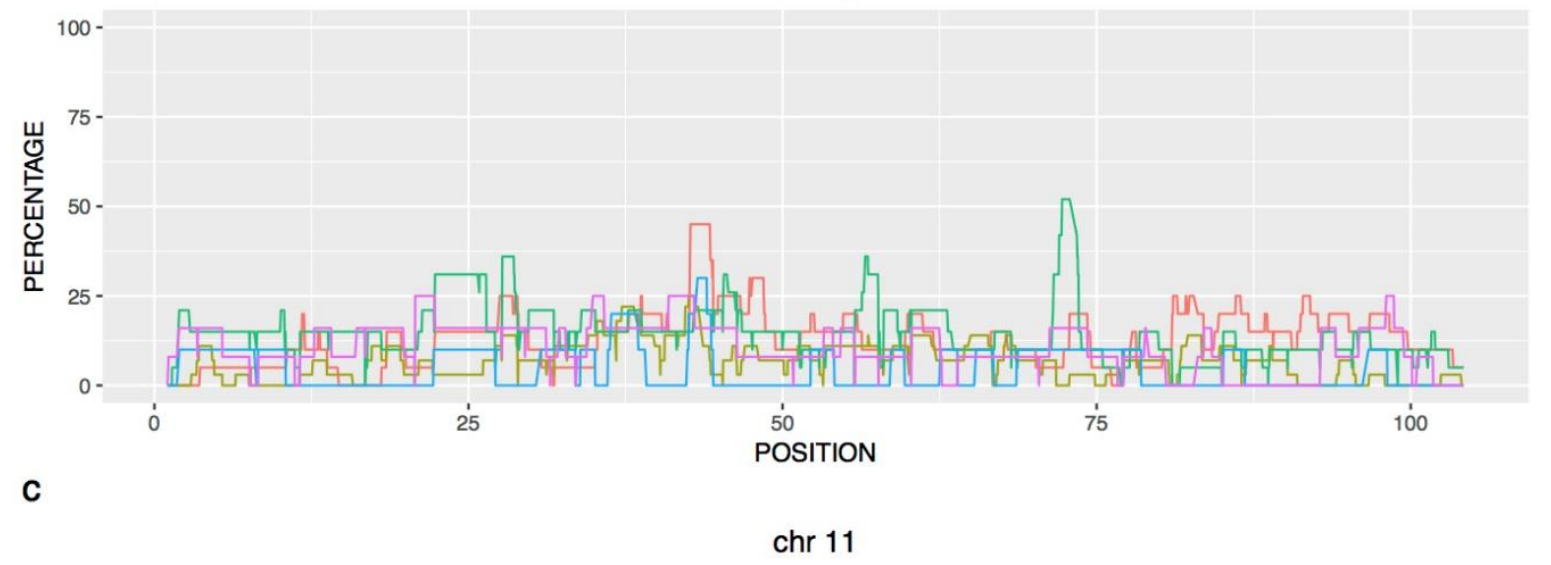

BREED

- BSW

- MOD

- SAR

- SB

- SM

100 -

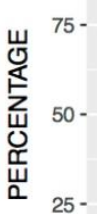

639

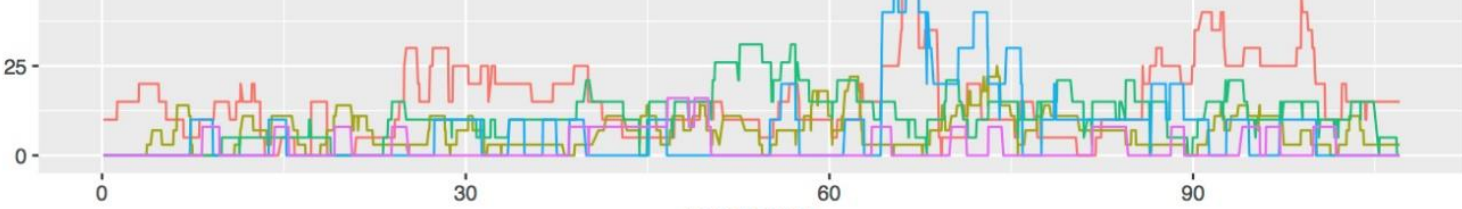

BREED

- BSW

- MOD

- SAR

- SB

- $\mathrm{SM}$

\section{$640 \quad$ Figure 6}

